\title{
Protection of large partitioned MTDC Networks Using DC-DC converters and circuit breakers
}

\author{
Md Habibur Rahman ${ }^{1}$, Lie X $\mathrm{U}^{1^{*}}$ (D) and Liangzhong $\mathrm{Yao}^{2}$
}

\begin{abstract}
This paper proposes a DC fault protection strategy for large multi-terminal HVDC (MTDC) network where MMC based DC-DC converter is configured at strategic locations to allow the large MTDC network to be operated interconnected but partitioned into islanded DC network zones following faults. Each DC network zone is protected using either AC circuit breakers coordinated with DC switches or slow mechanical type DC circuit breakers to minimize the capital cost. In case of a DC fault event, DC-DC converters which have inherent DC fault isolation capability provide 'firewall' between the faulty and healthy zones such that the faulty DC network zone can be quickly isolated from the remaining of the MTDC network to allow the healthy DC network zones to remain operational. The validity of the proposed protection arrangement is confirmed using MATLAB/SIMULINK simulations.
\end{abstract}

Keywords: DC circuit breaker, DC-DC converter, DC fault, HVDC, Modular multilevel converter (MMC), Network partition

\section{Introduction}

HVDC is an economic solution of transmitting large amount of power over a long distance compare to the traditional HVAC transmission system due to less transmission losses and smaller cable size for given power level. Voltage source converter (VSC) technology is becoming the main focusing area of recent HVDC research due to its inherent flexible ability of independent active and reactive power control, AC voltage support, and black-start capabilities [1, 2].

There are different network topologies to develop a large MTDC network. At present radial and meshed type network configurations are the most common ones. Radial network configuration is similar to the traditional AC distribution system. Meshed network configuration is more reliable than radial due to redundant supply channels but incur higher cable cost. Any topology can be configured, once technical and economic benefits of the network operators have been dealt with [3].

The major challenges towards the protection of an MTDC network in the event of a fault at the DC side of

\footnotetext{
* Correspondence: lie.xu@strath.ac.uk

${ }^{1}$ University of Strathclyde, Glasgow, UK

Full list of author information is available at the end of the article
}

the network include fault detection, fault location and isolation [4-6]. Due to low impedance of the DC network there is steep rise in fault current and fast DC voltage collapse which can potentially damage the power electronics converter and disrupt power transmission across the whole DC network. Therefore, a robust and accurate protection system is required which can detect the fault and its location and isolate the faulty section in a selective manner allowing fast restoration of the system following a DC fault [6-9].

Various protection strategies have been proposed for MTDC networks [10-14]. In [10] a handshaking' protection method for VSC based MTDC network is proposed where DC switch and AC circuit breakers (ACCBs) are used to protect the entire system though the complete network has to be shutdown and de-energized to allow the DC switches to isolate the faulty branches. The proposed concept can pose major operational problems for a large MTDC network and connected AC systems as the large 'loss of infeed' may cause large excursion in AC frequency. Thus, fast and reliable protection is mandatory for fast fault clearance to avoid complete shutdown of the entire network so as to minimize the disturbances to the connected AC networks. Some 
MMC topologies [15-17] can block or control DC fault current but resulting additional capital cost and power loss. In addition, such converter topologies cannot isolate fault from the MTDC network apart from protecting themselves from over-current so additional DC protection equipment is still required.

For MTDC network protection, different types of DC circuit breakers (DCCBs) such as slow mechanical DCCBs, solid state DCCBs and hybrid DCCBs, have been proposed $[18,19]$. Some DCCBs, e.g., solid state and hybrid types are capable of operating within a few milliseconds but to avoid complete shutdown of the entire MDTC network they will have to be used at every cable branch leading to excessively high capital cost, larger footprint and high on state losses (for solid state DCCB only). In contrast, slow mechanical DCCBs incur low capital cost and low loses [20].

DC-DC converters allow DC sections with different DC voltage levels to be interconnected. They can also isolate DC faults rapidly and allow the healthy part of the network remains operational. Various studies have been conducted with different DC-DC converter topology [21, 22] for MTDC network though its high capital cost and power loss, and larger footprint mean its use has to be carefully considered.

The main contribution of this paper is on the use of DC network partition but interconnected using DC-DC converters at strategic locations. The partitioned DC network zones can be protected by means of ACCBs, DC Switches and slow DCCBs depending on their individual network configuration. The main purpose of the protection arrangement is to minimize the use of expensive DCCBs and DC-DC converters to reduce the capital cost of large MTDC networks. The rest of the paper is structured as follows: Section II describes the fault behaviour of half bridge MMC based converters. Large MTDC network partition with protection arrangement is outlined in section III and detailed system configuration is considered in section IV. In section V, two case studies in Matlab/Simulink environment is performed to demonstrate the validity of the proposed protection arrangement and finally, section VI draws the conclusions.

\section{DC fault behavior}

In a MTDC network, a single DC fault can cause serious consequences due to low impedance of the DC network leading to high fault current propagating throughout the entire network that could enforce the complete shutdown of the network for prolonged period [23]. As soon as a DC fault occurs, there is a step rise in DC current due to the discharge of the DC cable capacitor and AC side current starts feeding through the freewheeling diodes which could cause damage to the power electronics devices [24]. There are various reasons, which can lead to a DC fault such as lightening strike in case of overhead lines, ship anchors for undersea cables, electrical stress, cable aging, physical damage, environmental stress etc.

To analyse the DC fault behaviour, an equivalent circuit of a half bridge MMC is shown in Fig. 1, and a number of stages can be considered which has been well documented in [25]. Unlike the conventional two-level VSCs, half bridge MMC experiences considerably lower DC fault current due to relatively small cable capacitance and absence of large DC link capacitors at converter terminals. A DC line-to-line fault is applied at $1.1 \mathrm{~s}$ and the MMC is blocked $1 \mathrm{~ms}$ after the fault initiation. Figure 2 illustrates the system response during the fault period. Long (Fig. 2(a)-(e)) and short (Fig. 2(f)-(j)) duration time-scale waveforms have been presented for ease of analysis. The DC link voltages depicted in Fig. 2(a) and (f) show immediate drop with oscillations after the fault initiation and reach to negative values due to the presence of the arm reactance. In the meantime, there is a step rise in the DC link current as shown in Fig. 2(b) and (g). Fig. 2(c), (h) and (d), (i) show the upper and lower arm currents respectively, and Fig. 2(e) and (j) show large AC fault currents feeding from the AC networks during the fault period. This AC fault current flows through the freewheeling diodes before being interrupted by the opening of the ACCB whose tripping time is set at $80 \mathrm{~ms}$ after the detection of $\mathrm{AC}$ over current.

\section{MTDC network partition and protection Network partition}

Significant challenges need to overcome to protect a large scale MTDC network in the event of a single DC fault. The straight forward solution is to install fast acting DCCBs at every DC cable connection points though it will incur huge cost in system protection. Therefore, a number of facts need to be considered while configuring a large MTDC network protection such as infrequency of DC fault events, inconsistency of power generation from wind farms and investment in protection cost. To rationalize the cost and reliable protection, a large MTDC network can be partitioned into a number of small DC network zones. In case of a fault event in a particular zone, the fault can be isolated by clearance from AC side protection and DC switches [13, 26, 27].

The acceptable permanent 'loss of infeed' is $1.8 \mathrm{GW}$ currently in UK according to the system operator in order to maintain network stability. The 'loss of infeed' could be due to a fault event or regular maintenance. Therefore, while partitioning a large MTDC network, each DC network zone should be configured in such a way that the total permanent 'loss of infeed' is kept below the maximum power loss criterion in the event of a fault. But this partitioning reduces the operational 


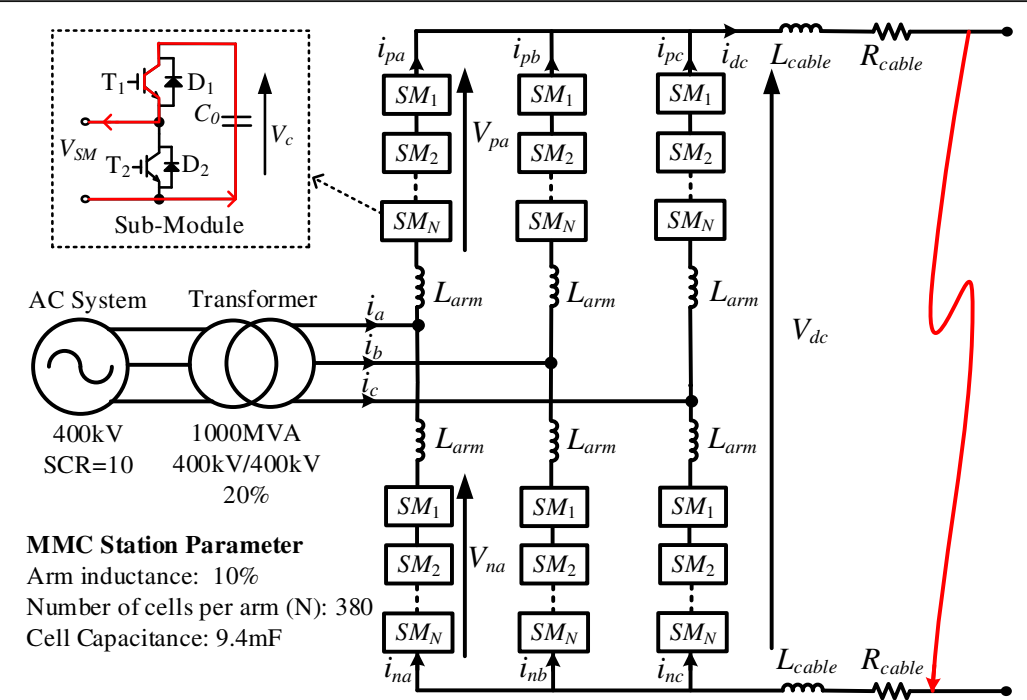

Fig. 1 Equivalent circuits of half bridge MMC during DC line-to-line fault
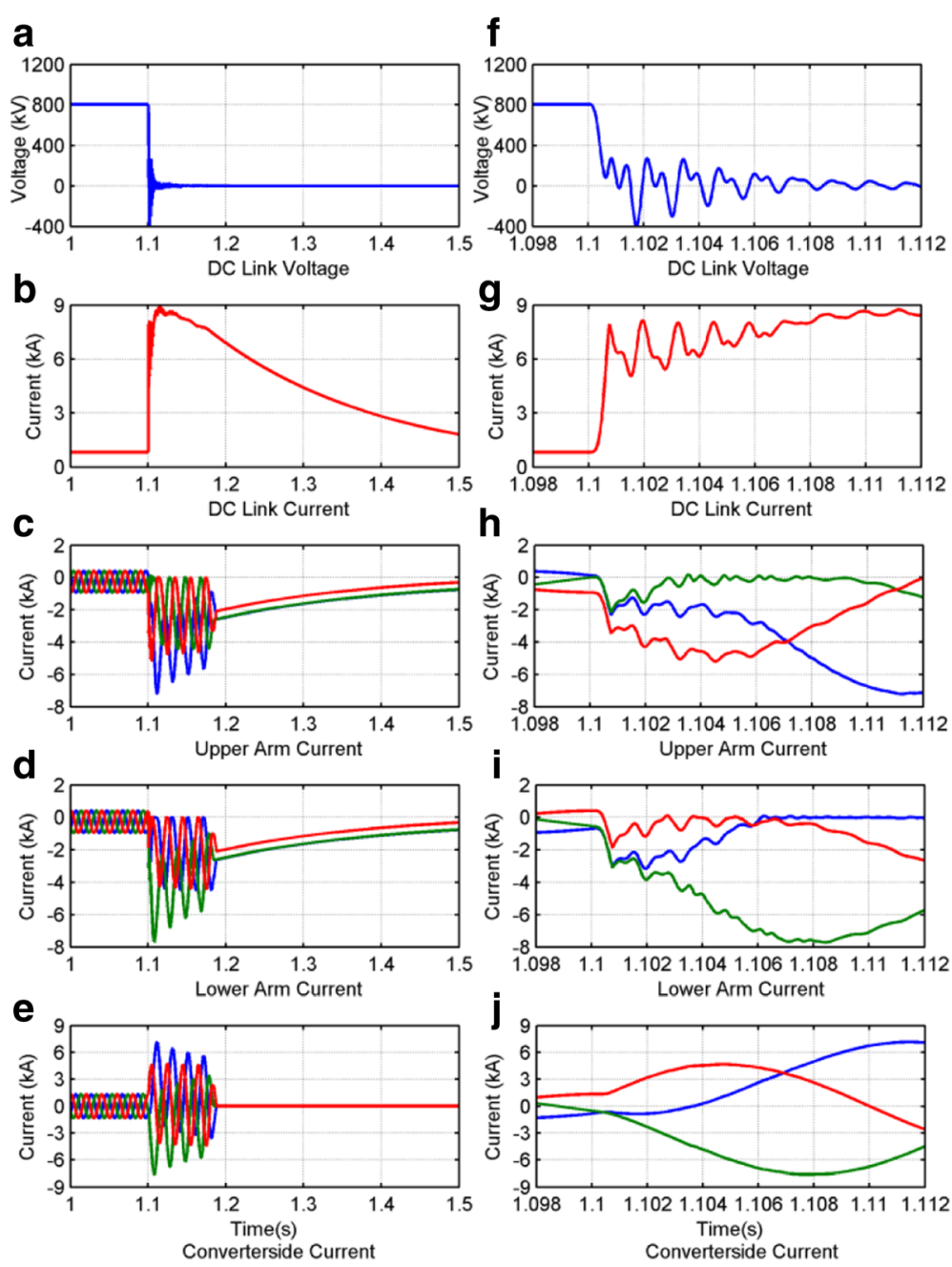

Fig. 2 Response from a half bridge MMC converter during DC line-to-line fault 
flexibility of the MTDC network. An alternative option to protect a large MTDC network is to use DC-DC converters located at strategic locations, joining different DC network zones allowing the entire network to be operated interconnected at pre-fault condition but partitioned into islanded DC network zones following any fault events. An example DC network configuration is shown in Fig. 3 where MMC based DC-DC converters are used. In case of a fault event in one of the DC network zones at least two DC network zones can remain operational. Each network zone can be protected using different protection arrangement depending on their configurations.

\section{Protection arrangement}

There are different options to clear the DC side faults without causing a large loss of infeed in a large MTDC network. The main purpose of this work is to keep the healthy zone in the large MTDC system operational all times following a DC fault by means of using DC-DC converter at strategic location. Each DC network zone can be protected using any combination of slow mechanical DCCBs, ACCBs and DC switches depending on the zone configuration. The following steps are considered for the proposed system to clear a DC fault allowing the healthy zones to remain operational:

Step 1: Using local current measurement in the converter arms and DC sides to detect the fault. Step 2: If converter arm currents reach above predetermined set value converter will be blocked. This applies to all the AC-DC and DC-DC converters and will isolate the faulty zone from the healthy ones.

Step 3: By opening the ACCBs and DC switches or the slow DCCBs in the faulty zone, the DC fault can be isolated.
Step 4: After isolating the faulty part within the faulty zone remaining part of the network can be restarted and can be reconnected to the healthy zones depending on fault location.

\section{System configuration}

Figure 4 shows the six-terminal MTDC system considered in the paper consisting of 6 half bridge MMCs connected to AC systems. The system contains two DC network zones (one radial and one meshed network respectively) which are interconnected by DC cables equipped with a DC-DC converter. No Fast acting DCCBs are used within any DC network zones so as to reduce the cost and power loss. Here DC network Zone $1( \pm 320 \mathrm{kV} \mathrm{DC})$ which is a radial network is protected using ACCBs and DC switches. As for the DC network Zone $2( \pm 400 \mathrm{kV} \mathrm{DC})$, a meshed network configuration is used with increased reliability due to redundant supply channels. For this DC Zone 2, slow mechanical DCCBs are installed.

The proposed protection arrangement is applied to the MTDC system shown in Fig. 4 and is verified in MATLAB/SIMULINK environment. The MMC converters are modeled as average value models which provide faster simulation speeds. The average MMC model consists of controllable voltage and current sources where additional semiconductor devices are added to replicate the same functionality during normal operation as well as fault event. In this system configuration $\pi$ model of the cable is considered.

\section{Simulation result}

The Station 2 and 4 are assigned to transmit $800 \mathrm{MW}$ and $700 \mathrm{MW}$ power to the DC grid, respectively. Both Station 3 and 6 transmit $400 \mathrm{MW}$ power to their respective AC grids whereas Station 1 and 5 regulate the

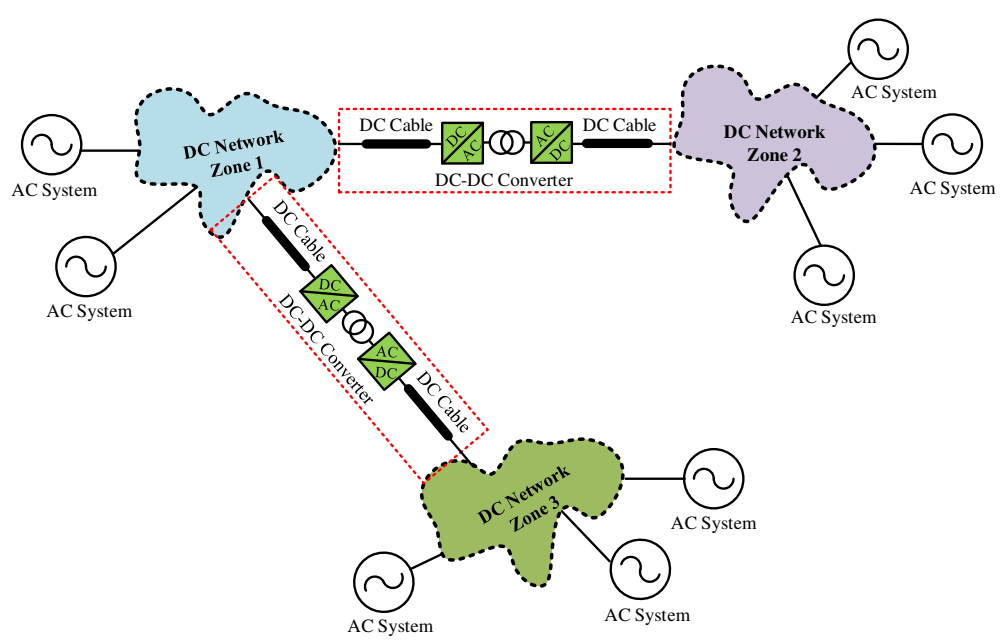

Fig. 3 Possible partitioned MTDC networks using DC-DC converters 


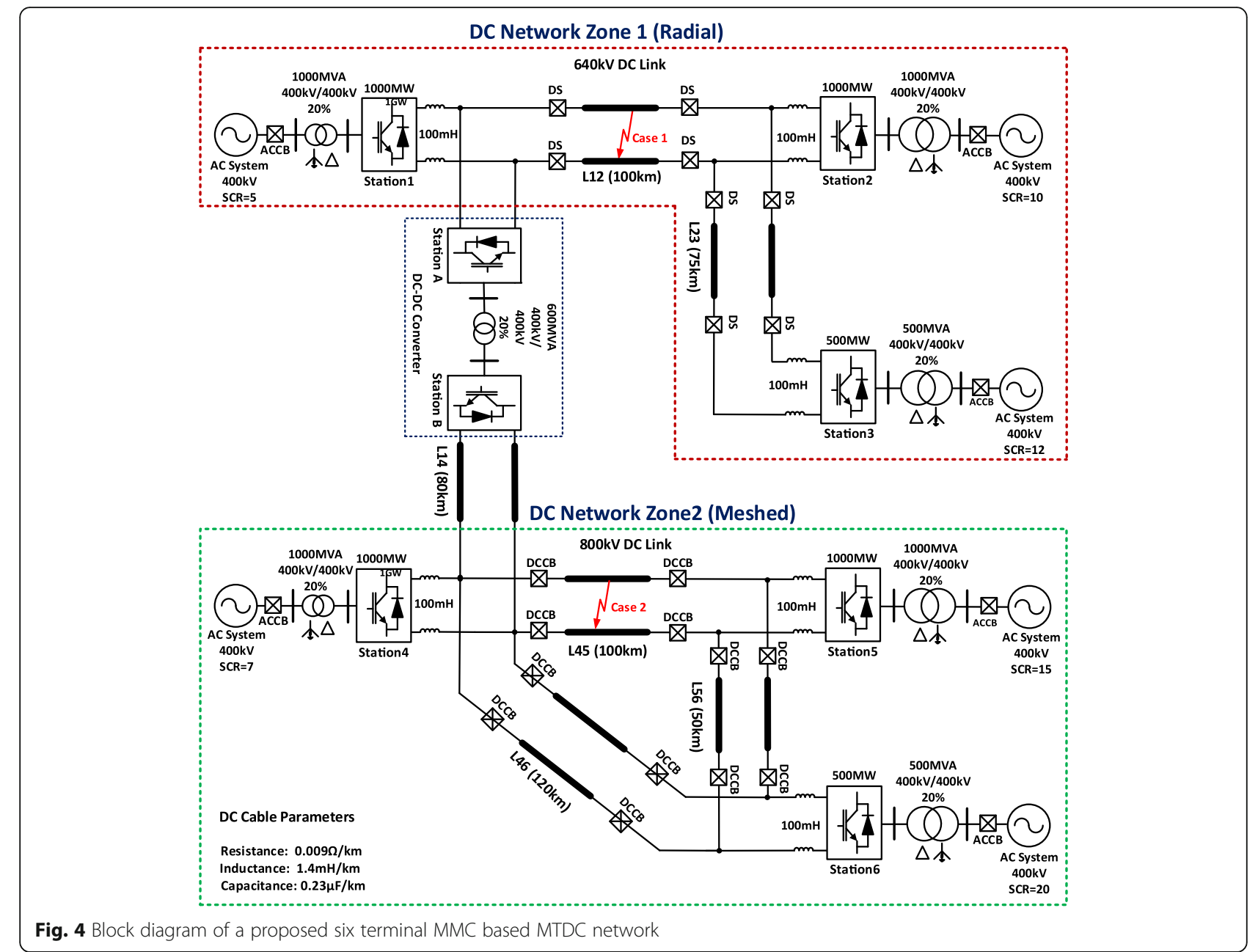

DC link voltages (640 kV and $800 \mathrm{kV}$ respectively) of DC Zone 1 and 2, respectively. The DC-DC converter's Station B (connected to Zone 2) is designed to transmit $200 \mathrm{MW}$ power from Zone 1 to Zone 2 while Station A (connected to Zone 1) is set for controlling the internal AC source voltage in the DC-DC converter. All converters operate at unity power factor for simplicity.

\section{Case 1-fault in zone 1}

When the system reaches its steady state condition, a DC line-to-line fault is applied at the time instant of $1.5 \mathrm{~s}$. The fault is placed at the midpoint of the transmission cable L12 and the protection system is in place throughout the network as required.

The main concept of protection arrangement in DC Zone 1 (radial network) is that, in case of any fault events within Zone 1, the DC-DC converter can quickly isolate the faulty Zone 1 by blocking its converter such that DC network Zone 2 can remain operational all the times. The faulty section in Zone 1 can then be isolated by means of using ACCBs and DC switches. In this case, after isolating the faulty section Station 1 is restarted to reconnect it to Zone 2 where Station 2 and 3 transmit power among themselves after restarting process.

The obtained results demonstrating the system's behavior are presented in Figs. 5, 6 and 7 for DC voltage, DC currents, and arm currents, respectively. It is obvious from Figs. 5 and 6 that the DC voltages in Zone 1 (all stations) are severely affected after fault initiation leading to a step increase in the DC link current. The $\mathrm{DC}$ over current flowing through the DC-DC converter (not shown due to space limitation) is quickly detected resulting an immediate blocking of the DC-DC converter which isolates Zone 1 from Zone 2. Apart from the loose of $200 \mathrm{MW}$ previously transmitted from Zone 1 to Zone 2 through the DC-DC converter which results in the change of the power (DC current) for Station 5 (DC voltage controller) it is evident that there is insignificant impact on the DC voltages in Zone 2 due to the fast blocking of the DC-DC converter.

Figure 7 represents the upper arm currents. In this proposed system, fault is detected in the DC-DC converter and each AC-DC converters located in Zone 1 when their respective arm currents exceed pre-defined 


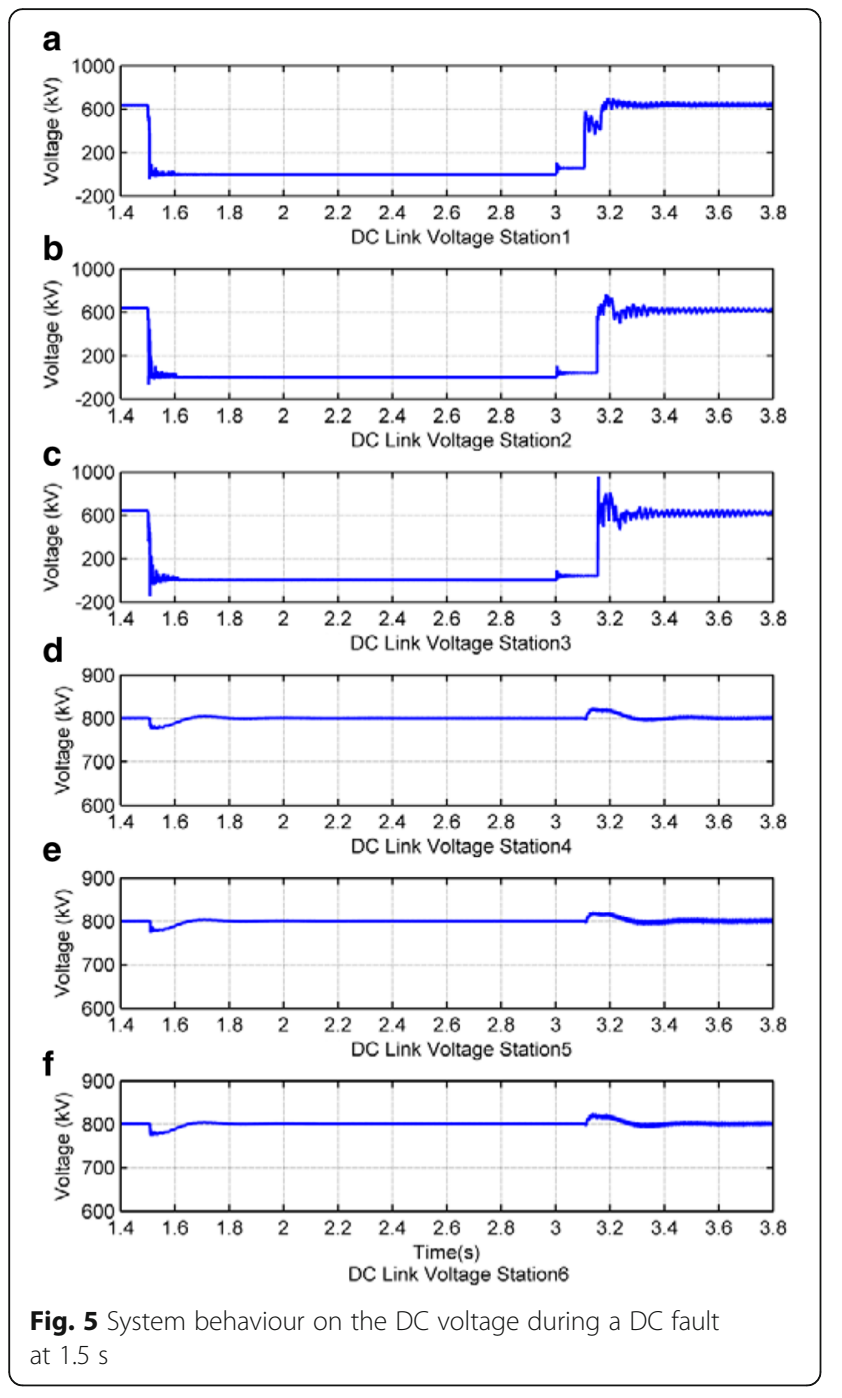

maximum values. In this simulation study Station $1-3$ and DC-DC converter stations are blocked at $7 \mathrm{~ms}, 4 \mathrm{~ms}$, $8 \mathrm{~ms}$ and $7 \mathrm{~ms}$ respectively after the fault initiation. After blocking the converter arm currents continue increasing (see Fig. 7) through the freewheeling diodes.

In this study the ACCBs equipped in Station 1-3 are opened at $107 \mathrm{~ms}, 104 \mathrm{~ms}$ and $108 \mathrm{~ms}$ respectively, after the fault initiation (including $100 \mathrm{~ms}$ delay). Upon opening the ACCBs the converter arm currents in station 1-3 are gradually brought to zero as shown in Fig. 7 . The DC current in Zone 1 can take considerable time to decay as evident in Fig. 6 due to the low resistance in the DC cables.

System recovery process is one of the key factors for a large MTDC system. It is worth noted that loss of a transmission line due to fault results in a reduction in overall power capacity of the MTDC network leading to a direct consequence on the remaining healthy lines of the network.
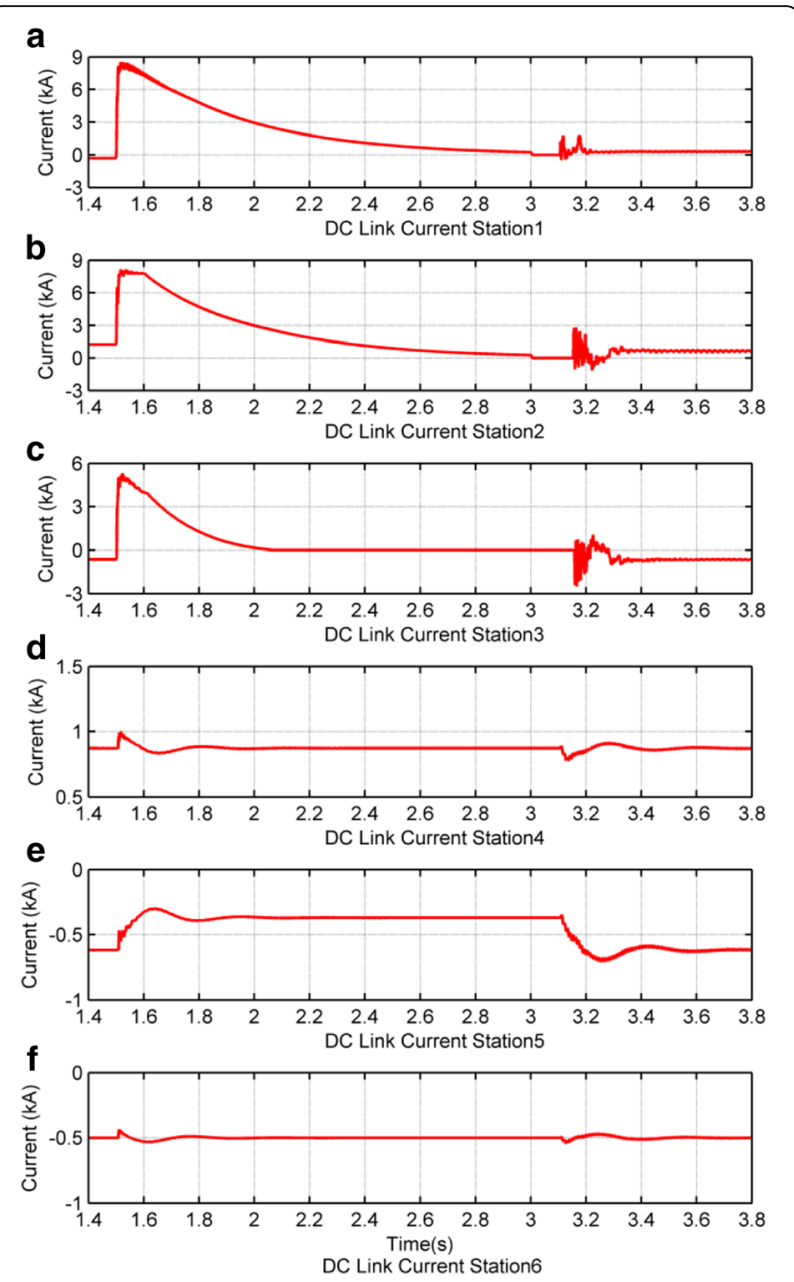

Fig. 6 System behavior on the DC Current during a DC fault at $1.5 \mathrm{~s}$

Proper power rescheduling is required to ensure stable system operation during system recovery process. In this simulation, the faulty transmission cable L12 are disconnected by DC switches which are opened when the DC link current of the faulty cable reaches approximately zero. Here DC switches are opened at around $3 \mathrm{~s}$ (1.502 ms after fault initiation). Once the faulty part is cleared from Zone 1, all ACCBs are reclosed again for Station $1-3$ at $3.057 \mathrm{~s}, 3.054 \mathrm{~s}$ and $3.058 \mathrm{~s}$ respectively. Then Station 1 and the DC-DC converter are restarted at $3.1 \mathrm{~s}$ to reconnect with DC network Zone 2. The transmitted power from Station 1 through the DC-DC converter to Zone 2 is again set at $200 \mathrm{MW}$ after recovery.

As can be seen in Fig. 6, the DC link current at the DC voltage controller, i.e., Station 5, changes accordingly. Station 2 and 3 are restarted at $3.154 \mathrm{~s}$ and $3.158 \mathrm{~s}$ respectively to transmit power among the two. Here Station 2 controls the DC link voltage and Station 3 regulates active power at $400 \mathrm{MW}$. The complete system reaches in steady state within $400-500 \mathrm{~ms}$ after the 


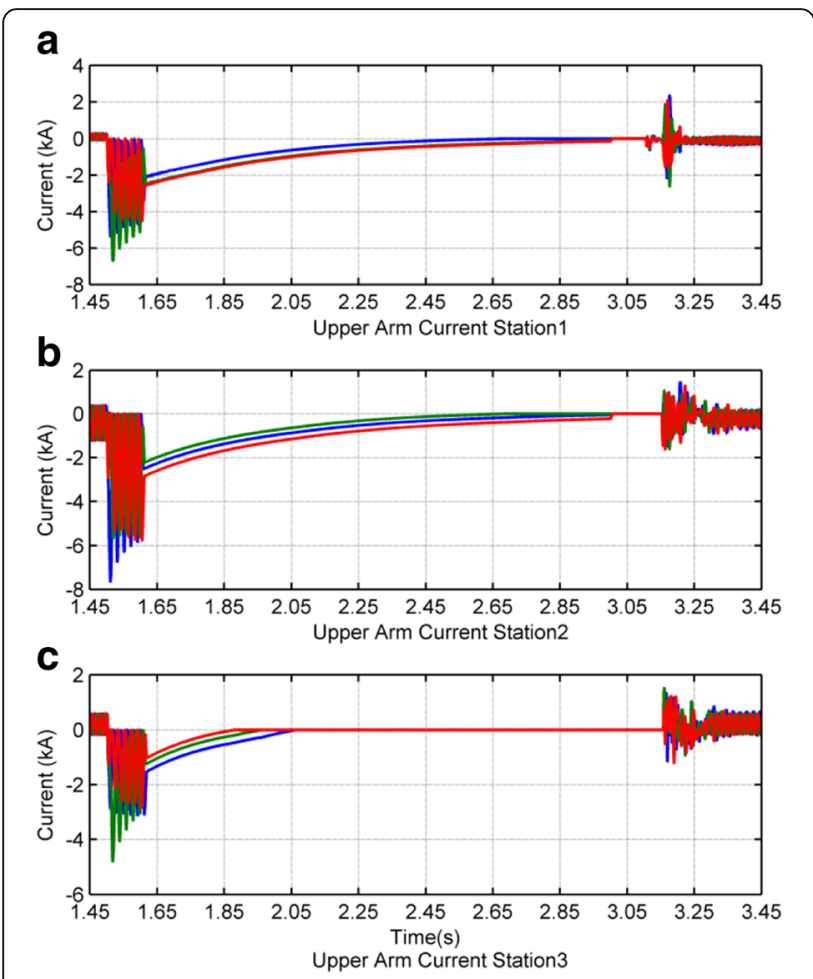

Fig. 7 Upper arm currents during a DC fault at $1.5 \mathrm{~s}$

recovery process. The obtained results presented in Figs. 5, 6 and 7 clearly show satisfactory protection and restoration process.

\section{Case 2 -fault in zone 2}

The fault is placed at $1.5 \mathrm{~s}$ at the midpoint of the transmission cable L45. The main concept of this protection arrangement in DC network Zone 2 (meshed network) is that, in case of any fault events within Zone 2, the DC-DC converter can quickly isolate the faulty zone by blocking its converter such that the DC network Zone 1 can remain operational all the times. Fault section with the faulty Zone 2 can then be isolated by means of using slow DCCBs. In this case, after isolating the faulty section all stations in Zone 2 are restarted and are reconnected with Zone 1.

The obtained results demonstrating the system's behavior are presented in Figs. 8, 9 and 10 for the DC link voltages, DC link currents, and arm currents, respectively. Long and short duration time-scale waveforms have been presented for ease of analysis. It can be seen from Figs. 8 and 9, that the DC voltages at all station in Zone 2 are severely affected after fault initiation leading to step increases in DC link currents. The DC over current flowing through the DC-DC converter is quickly detected resulting an immediate block of the DC-DC converter isolating Zone 2 from the healthy Zone 1 . It is evident that there is little
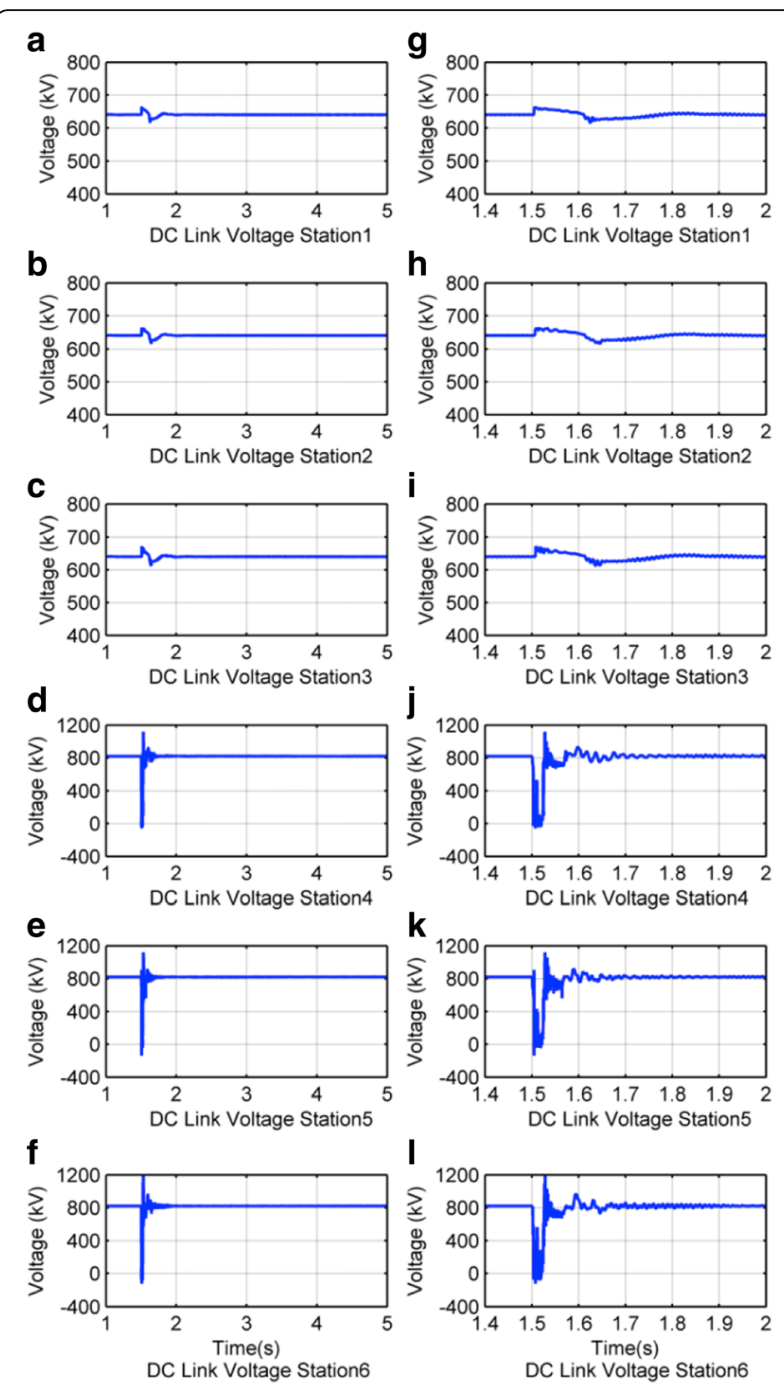

Fig. 8 System behavior on the DC voltage during a DC fault at $1.5 \mathrm{~s}$

impact on DC Zone 1 apart from the temporary reschedule of the power flow as Station 1 has to transmit the extra $200 \mathrm{MW}$ previously flowing through the DC-DC converter to Zone 2.

Figure 10 represents the upper arm currents. In the proposed system, faults are detected in each converter located in Zone 2 and the DC-DC converter using automatic arm over-current detection and blocking method. In the simulation Station 4-6 and the DC-DC converter are blocked at $3 \mathrm{~ms}, 4 \mathrm{~ms}, 4 \mathrm{~ms}$ and $4 \mathrm{~ms}$ respectively after the fault initiation.

After blocking the converter, the arm currents continue increasing (see Fig. 10) through the freewheeling diodes. Here Zone 2 is protected using slow mechanical DCCBs. In this simulation study the slow DCCBs are opened with $20 \mathrm{~ms}$ mechanical delay after over-current detection and only those DCCBs whose detected overcurrents flow into the connected DC cables are opened. 


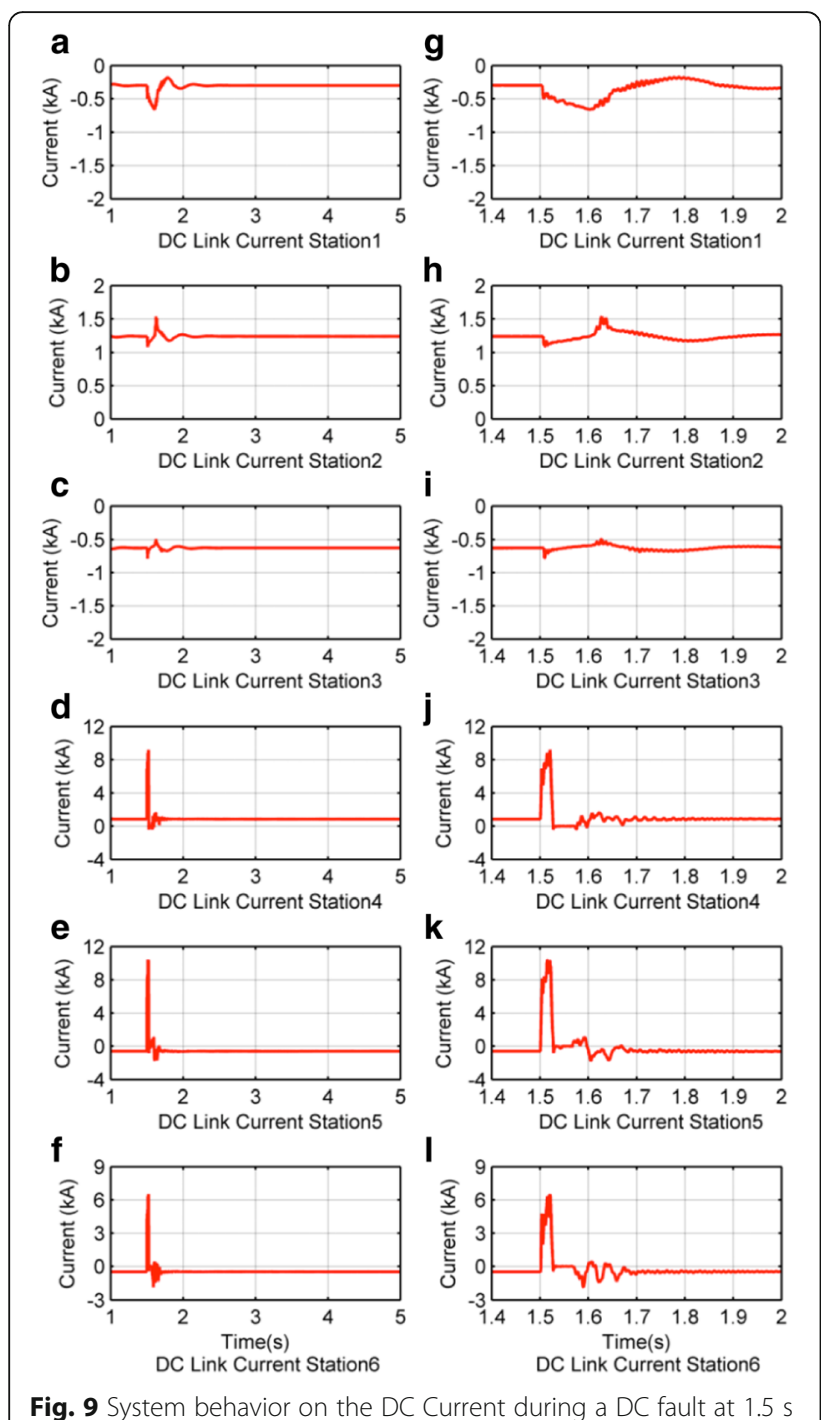

As the fault is in cable L45, DCCBs at both ends of L45 will see current flowing into the fault and whereas for other cables (i.e., L46 and L56) only DCCBs at one side of each cable see fault current flowing into the cable. Therefore, L45 will be completely isolated by the DCCBs whereas L46 and L56 only disconnect on one ends. Upon the opening of the DCCBs the DC link currents and converter arm currents in Station 4-6 are quickly brought to zero (see Figs. 9 and 10).

System recovery process for Case 2 is quicker than Case 1 due to the different protection arrangements installed in Zone 2 (DCCBs) compared to that of Zone 1 (ACCBs and DC switches). After the faulty cables L45 are disconnected by opening the relevant mechanical DCCBs all others DCCBs (meaning L46 and L56) are reclosed again for restoration of Station $4-6$ at $73 \mathrm{~ms}$, $64 \mathrm{~ms}$ and $69 \mathrm{~ms}$ respectively. Then the DC-DC converter is restarted at $104 \mathrm{~ms}$ for normal operation
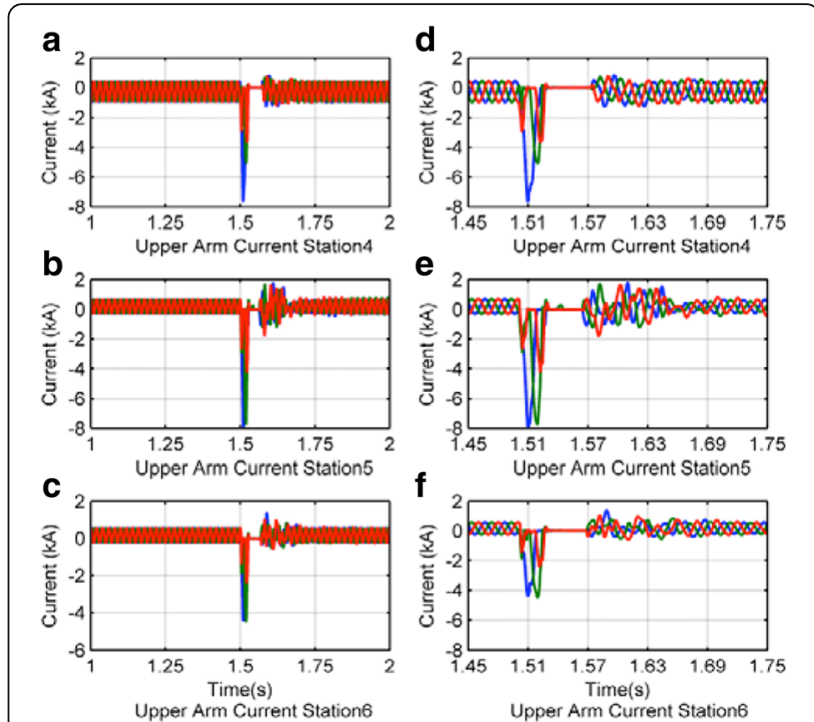

Fig. 10 Upper Arm currents during a DC fault at $1.5 \mathrm{~s}$

reconnecting Zone 1 and 2 where the same pre-fault $200 \mathrm{MW}$ is transmitted from Zone 1 to Zone 2. All Stations in Zone 2 are operated as their pre-fault control modes. The entire MTDC network transmits the same amount of power after losing one cable (L45) due to meshed configuration in Zone 2. The system's restoration process presented in Figs. 8, 9 and 10, gives satisfactory performance. In this simulation study, the system is reached in steady state within $80-100 \mathrm{~ms}$ after the recovery process.

\section{Conclusion}

Partition of a large MTDC network into different DC network zones is proposed where DC-DC converters installed at strategic locations allowing interconnected network operating with inherent DC fault isolation and 'firewall' between the different DC zones. This proposed protection configuration ensures accurate and robust protection option for the system with low investment in protection cost, and continuous operation of the healthy zones during a fault event in other zone of the MTDC network is achieved. The simulation results corresponding to DC fault protection have been presented for a MTDC network containing one radial DC zone and one meshed DC zone, and give satisfactory results. The proposed concept can be an attractive approach to interconnect various grids to form a large MTDC network in future.

\section{Acknowledgment}

This work is supported in part by China Electric Power Research Institute (CEPRI).

\section{Authors' contributions}

MHR carried our the simulation studies and drafted the manuscript. LX and LY provided technical leadership to the studies. All authors read and approved the final manuscript. 


\section{Competing interests}

The authors declare that they have no competing interests.

\section{Author details}

${ }^{1}$ University of Strathclyde, Glasgow, UK. ${ }^{2}$ China Electric Power Research Institute, Beijing, China.

Received: 28 July 2016 Accepted: 17 November 2016

Published online: 12 December 2016

\section{References}

1. $\mathrm{Xu}$, L., \& Andersen, B. (2006). Grid integration of large offshore wind farms using HVDC. Wind Energy, 9, 371-382.

2. Kirby, N. M., Xu, L., Luckett, M., \& Siepmann, W. (2002). HVDC transmission for large offshore wind farms. IET Power Engineering Journal, 16, 135-141.

3. Maclver, C., Bell, K. R. W., \& Nedic, D. P. (2015). A reliability evaluation of offshore HVDC grid configuration options. IEEE Transactions on Power Delivery, $P P, 1$.

4. Yan, X., Difeng, S., \& Shi, Q. (2013). Protection coordination of meshed MMCMTDC transmission systems under DC faults. In TENCON 2013-2013 IEEE Region 10 Conference (31194) (pp. 1-5).

5. Yousefpoor, N., Kim, S., \& Bhattacharya, S. (2014). Control of voltage source converter based multi-terminal DC grid under DC fault operating condition. In Energy Conversion Congress and Exposition (ECCE), 2014 IEEE (pp. 5703-5708).

6. Tang, L., \& Ooi, B.-T. (2002). Protection of VSC-multi-terminal HVDC against DC faults. In Power Electronics Specialists Conference, 2002. pesc 02. 2002 IEEE 33rd Annual (Vol. 2, pp. 719-724).

7. Lu, W., \& Ooi, B.-T. (2003). DC overvoltage control during loss of converter in multiterminal voltage-source converter-based HVDC (M-VSC-HVDC). IEEE Transactions on Power Delivery, 18, 915-920.

8. Yang, J., Fletcher, J. E., \& O'Reilly, J. (2010). Multiterminal DC wind farm collection grid internal fault analysis and protection design. IEEE Transactions on Power Delivery, 25, 2308-2318.

9. Rafferty, J., Xu, L., \& Morrow, D. J. (2015). Analysis of VSC-based highvoltage direct current under DC Line-to-earth fault. IET Power Electronics, 8(3), 428-438

10. Tang, L., \& Ooi, B.-T. (2007). Locating and Isolating DC faults in multiterminal DC systems. IEEE Transactions on Power Delivery, 22, 1877-1884.

11. Hajian, M., Jovcic, D., \& Bin, W. (2013). Evaluation of semiconductor based methods for fault isolation on high voltage DC grids. IEEE Transactions on Smart Grid, 4, 1171-1179.

12. Jovcic, D., Taherbaneh, M., Taisne, J. P., \& Nguefeu, S. (2015). Offshore DC Grids as an interconnection of radial systems: protection and control aspects. IEEE Transactions on Smart Grid, 6, 903-910.

13. Rahman, M. H., Xu, L., \& Bell, K. (2015). DC fault protection of multiterminal HVDC systems using DC network partition and DC circuit breakers. In Protection, Automation and Control World Conference(PACWorld2015) (pp. 1-10).

14. R Li, L Xu, D Holliday, F Page, S Finney, and B Williams. (2016). "Continuous operation of radial multi-terminal HVDC systems under DC Fault". Power Delivery IEEE Transactions, 31, 351-361.

15. Marquardt, R. (2011). Modular multilevel converter topologies with DC-short circuit current limitation. In Power Electronics and ECCE Asia (ICPE \& ECCE), 2011 IEEE 8th International Conference (pp. 1425-1431).

16. Zeng, R., Xu, L., Yao, L., \& Williams, B. W. (2015). Design and operation of a hybrid modular multilevel converter. IEEE Transactions on Power Electronics, 30, 1137-1146.

17. Rui, L., Adam, G. P., Holliday, D., Fletcher, J. E., \& Williams, B. W. (2015). Hybrid cascaded modular multilevel converter with DC fault ride-through capability for the HVDC transmission system. IEEE Transactions on Power Delivery, 30, 1853-1862.

18. Franck, C. M. (2011). HVDC circuit breakers: a review identifying future research needs. IEEE Transactions on Power Delivery, 26, 998-1007.

19. Tahata, K., El Oukaili, S., Kamei, K., Yoshida, D., Kono, Y., Yamamot, R., et al. (2015). HVDC circuit breakers for HVDC grid applications. In AC and DC Power Transmission, 11th IET International Conference (pp. 1-9).

20. F Page, S Finney, and $L X u$. "An alternative protection strategy for multiterminal HVDC". In: 13th Wind Integration Workshop. Energynautics GmbH: Berlin; 2014
21. Zeng, R., Xu, L., \& Liangzhong, Y. (2015). DC/DC converters based on hybrid MMC for HVDC grid interconnection. In AC and DC Power Transmission, 11th IET International Conference (pp. 1-6).

22. Jovcic, D., Taherbaneh, M., Taisne, J. P., \& Nguefeu, S. (2014). Developing regional, radial DC grids and their interconnection into large DC grids. In PES General Meeting Conference \& Exposition, 2014 IEEE (pp. 1-5).

23. Chang, B., Cwikowski, O., Barnes, M., \& Shuttleworth, R. (2015). Multi-terminal VSC-HVDC pole-to-pole fault analysis and fault recovery study. In AC and DC Power Transmission, 11th IET International Conference (pp. 1-8).

24. Rafferty, J., Xu, L., \& Morrow, D. J. (2012). DC fault analysis of VSC based multi-terminal HVDC systems. In AC and DC Power Transmission (ACDC 2012), 10th IET International Conference (pp. 1-6).

25. Gao, Y., Bazargan, M., Xu, L., \& Liang, W. (2013). DC fault analysis of MMC based HVDC system for large offshore wind farm integration. In Renewable power generation conference (RPG 2013), 2nd IET (pp. 1-4).

26. Bell, K. R. W., Xu, L., \& Houghton, T. (2015). Considerations in design of an offshore network. In CIGRE Science and Engineering (pp. 79-92).

27. CD Barker, RS Whitehouse, AG Adamcyzk, and M Boden. "Designing fault tolerant HVDC networks with a limited need for HVDC circuit breaker operation'. Cigre General session: Paris; Paper B4-112: 2014.

\section{Submit your manuscript to a SpringerOpen ${ }^{\circ}$ journal and benefit from:}

- Convenient online submission

- Rigorous peer review

- Immediate publication on acceptance

- Open access: articles freely available online

- High visibility within the field

- Retaining the copyright to your article

Submit your next manuscript at springeropen.com 